\title{
Enhancing the Performance of Dynamic Source Routing Protocol by Modifying the Algorithm in Mobile ad-hoc Network
}

\author{
Temesgen Mengistu Helana \\ Department of Computer Science \\ School of Informatics \\ Wolaita Sodo University, WSU \\ Wolaita Sodo, Ethiopia
}

\author{
Alazar Merdekios Keba \\ Computer Science department \\ School of Informatics \\ Wolaita Sodo University, WSU \\ Wolaita Sodo, Ethiopia
}

\begin{abstract}
In our day-to-day life, wireless technology plays a great role, because users move from place to place across the globe, it's important to think about the type of network we can deploy quickly. Collection of two or more node forms A mobile ad-hoc network (MANET) without the aid of any centralized infrastructure. There are independent nodes that communicate without a wire in a mobile ad hoc network. Due to the behavior of nodes in MANET the time when node joining/leaving the network is unknown. This study focuses on improve performance of DSR protocol affected due to selfish nodes. So, identify path without any selfish node is the main issue for delivering a packet by selecting a reserved path. The algorithm counts the number of failed route request messages to aware the selfish node that causes failure on NS-2 simulator tools. The node is assigned to indicating the selfishness status of the node during route discovery. In this study the researcher conducts performance evaluation of existing DSR and modified one is assessed by using packet delivery ratio, and endto-end delay metrics and achieved very good result.
\end{abstract}

Keywords: - Dynamic Source Routing (DSR), Mobile AdHoc Network (MANET), Network Simulator (NS-2), Selfish Node

\section{INTRODUCTION}

A mobile ad-hoc network (MANET) is a type network in which mobile devices connected by wireless links [1]. Since the mid-1990s Mobile ad hoc networks (MANETs) has become popular areas of research because of the growth of personal computers, mobile devices, and 802.11/Wi-Fi wireless networking [3]. We are going to work on routing, and how node communication is going on with multiple nodes. Mobile nature of those nodes, node behavior, and another factor can change the link quality within a minor.

The major contribution of this thesis is to reduce performance problems due to misbehaved node by identifying the selfish node during route discovery before selecting path in Dynamic source routing. Therefore, node behavior based routing protocols is important to choose the stable route for passing through the available links. This approach deals with understanding the existed nodes in the network, modeling out node behavior of the network by observing pre and post characteristics of the nodes done for partitioning the approach into the proactive and reactive approach. For load balancing, easy to manage and control the greedy node as studied in [5]. MANET use different protocols for routing mechanism. Protocols in MANET are classified into Proactive (Table driven) and Reactive (on Demand) [2]. In Proactive (Table driven) type of MANET protocol, the routing information is usually kept in their routing tables and updates their information at a fixed time interval; such as Destination Sequenced Distance Vectored (DSDV), Cluster-head Gateway Switch Routing (CGSR), Optimized Link State Routing (OLSR) [1,2]. On the other hand, the Reactive (on Demand) one is designed for maintaining the information for active routes only; such as Ad-hoc on-demand routing protocol (AODV) and Dynamic Source Routing Protocol (DSR) [2].

\section{A. Routing Protocols In MANET}

From Mobile ad hoc network area routing protocol improvement and add new protocol take attention.it is limited to communicate with a single node with neighbor node without routing protocol. MANET uses Routing Protocols to discover and maintain a route between the source node to the destination node and the data packets process in the discovered path. In general, Routing protocols in MANET can be classified into the following categories [4]:

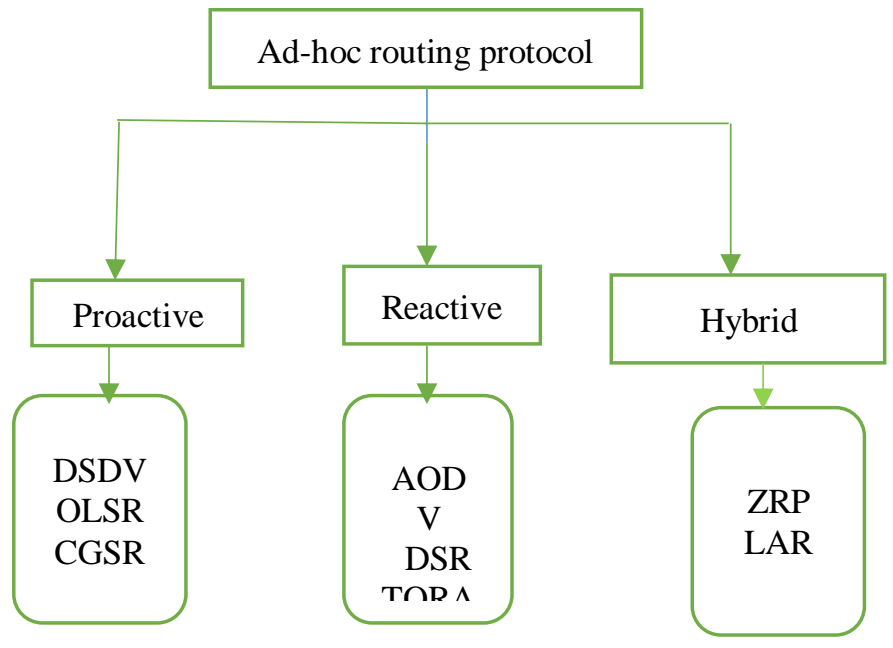

Fig 1:- End to end packet delay 


\section{OBJECTIVE OF THE STUDY}

\section{A. General Objective}

The general objective of this study is to improve performance in DSR routing protocol to overcome data loss, stability of a link/network for providing efficient services and initializing the reserved path to deliver the packet.

\section{B. Specific Objectives}

Specifically, the proposed work meets the following objectives.

$>$ To modified DSR by adding a selfish node identifying algorithm during routing path discovery.

To simulate the proposed algorithm by adding it to existing one

$>$ Performance evaluation and, compare the proposed solution with recent modified DSR.

\section{MODIFYING DYNAMIC SOURCE ROUTING PROTOCOL (DSR) DESCRIPTION}

The existed protocol does not hear/catch when a link failure occurs due to the misbehavior node, which drops a packet. This study designs an algorithm that detects link failure on DSR protocol through direct observation of the behavior of a mobile node to each other. The new proposed algorithm is patched in ns-2.35 within the existed DSR protocol. The study presents the Implementation of the new developed algorithm by modifying dsragent.cc, dsragent.h files for route reply and route request function in NS2-35.

\section{PSEUDO CODE OF PROPOSED ALGORISM}

The proposed algorism that were implemented in the modified dynamic source routing (DSR) protocol was illustrated in the following pseudo code.

Input: Total Number of Nodes Val (nn), node (i) intermediate node

Output: Routing handover procedure to simulate link status: Set Source Node: S // Source Nodes

Set Destination Node: D // Destination Node

For i 0 to $\mathrm{Val}(\mathrm{nn})$

\# Discover the routing table

If val (nn) sends Hello message

Then val (nn) stores network information.

If $\mathrm{S}$ sends RREQ message to D

If $\mathrm{D}$ is next to $\mathrm{S}$

Then $\mathrm{S}$ directly connected to $\mathrm{D}$

Else if node (i) rebroadcast on behalf of $\mathrm{S} / /$ intermediate node

Then path is discovered

If $S$ RERR

Then the path is not discovered

If $\mathrm{RERR}<=2$

Then $\mathrm{S}$ sends RREQ to val (nn)

Else node (i) node identifies as packet drop node \# $\mathrm{RERR}==3$ node $(\mathrm{i})$
Then All valid path is checked, node_id is discarded from route information

Else All valid paths are saved

In pseudo-code, $\mathrm{S}$ is the source node calculating its routing table, the source node gets RERR to form the predecessor and counts the number of dropped RREQ message, because routing table is updated continuously and each node knows their neighbors, then route from source to destination can be searched by another intermediate node.

\section{DEVELOPMENT ENVIRONMENT}

\section{A. Developing Ns2 Based Simulation}

Implementation purpose we used different tools such as NS-2 (Network simulator version 2) TCL, and C++ programing language is used and others are described table 1 and table 2 .

\begin{tabular}{|c|c|c|}
\hline S. no. & Name tools & Purpose \\
\hline 1. & NS2.35 & $\begin{array}{c}\text { The main network simulation } \\
\text { environment }\end{array}$ \\
\hline 2. & NSG2.1 & $\begin{array}{l}\text { Designing nodes and } \\
\text { Generating .tcl code }\end{array}$ \\
\hline 3. & $\begin{array}{c}\text { Sublime text } \\
2.0 .2\end{array}$ & $\begin{array}{c}\text { For OTCL and C++ } \\
\text { programming (.tcl, .cc, .h) } \\
\text { editor }\end{array}$ \\
\hline 4. & Nam.exe & $\begin{array}{c}\text { Simulation [network animation } \\
\text { ) }\end{array}$ \\
\hline 5. & Cygwin & To execute trace file (.tcl) \\
\hline 6. & $\begin{array}{c}\text { GNUPLOT } \\
5.2\end{array}$ & Generating graphs \\
\hline 7. & $\begin{array}{l}\text { NetBeans } \\
\text { (Java) } 8.02\end{array}$ & $\begin{array}{l}\text { To manipulate .tr file to } \\
\text { evaluate performance metrics }\end{array}$ \\
\hline
\end{tabular}

\section{Table 1}

\section{B. Simulation Setup And Settings}

\begin{tabular}{|c|c|}
\hline Parameter & Value \\
\hline Simulator tool & $\begin{array}{c}\text { Network simulator 2 } \\
\text { (NS-2) }\end{array}$ \\
\hline Simulation Area & 800 X 800 \\
\hline Number of Nodes & $\mathbf{2 0}$ \\
\hline Packet size & 512 byte \\
\hline Traffic type & CBR(Constant Bit Rate) \\
\hline Mobility & RWP \\
\hline Simulation time & $\mathbf{1 5 0}$ sec \\
\hline Interference range & $\mathbf{5 0 0}$ \\
\hline Antenna & Omni antenna \\
\hline
\end{tabular}

Table 2 


\section{RESULT AND DISCUSSION}

The result captured from the experimental activity in case both parameters such as packet delivery ration and endto-end packet delay.

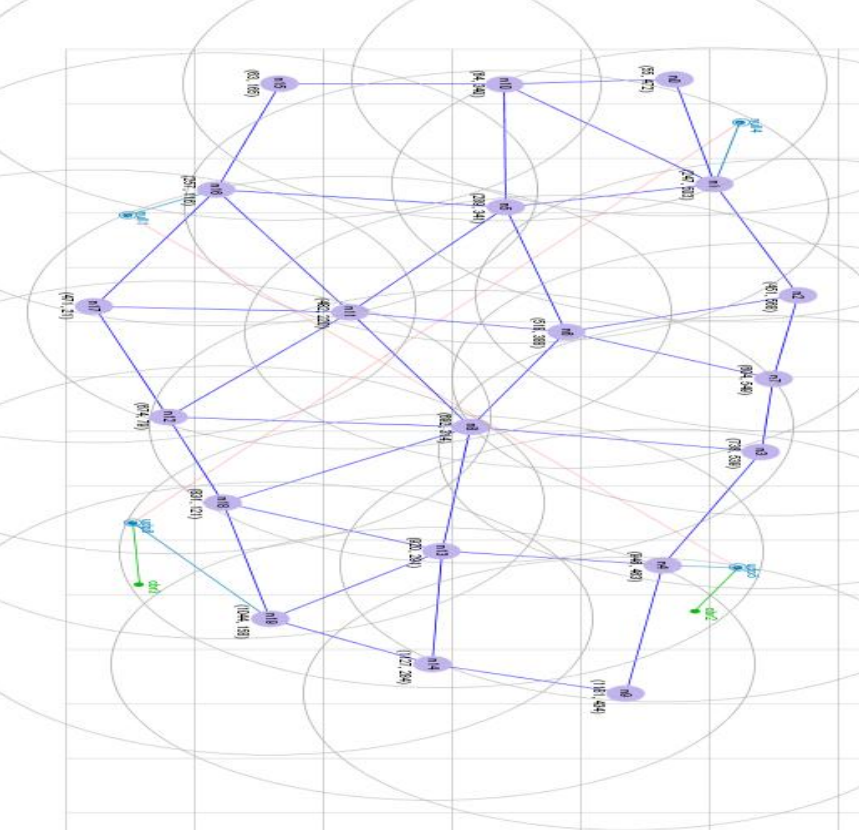

Fig 2:- Number of nodes used for simulation designed on NSG2.1

The screenshot image of tcl code is the sample code written in sublime code editor.

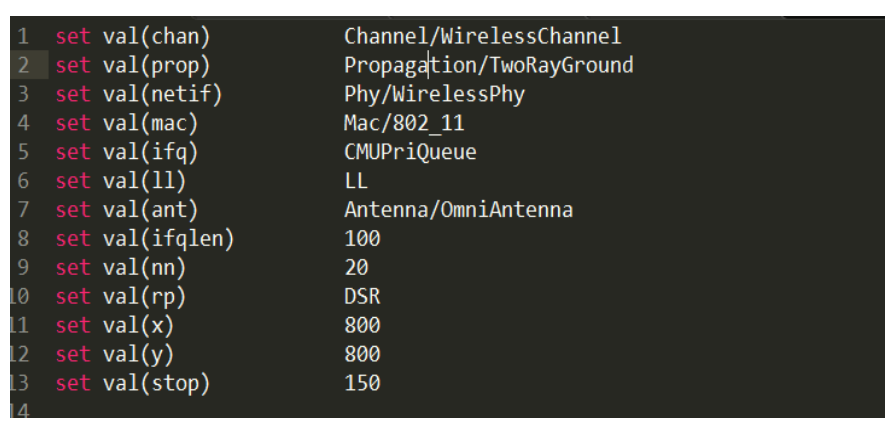

Fig 3:- Sample tcl code screenshot

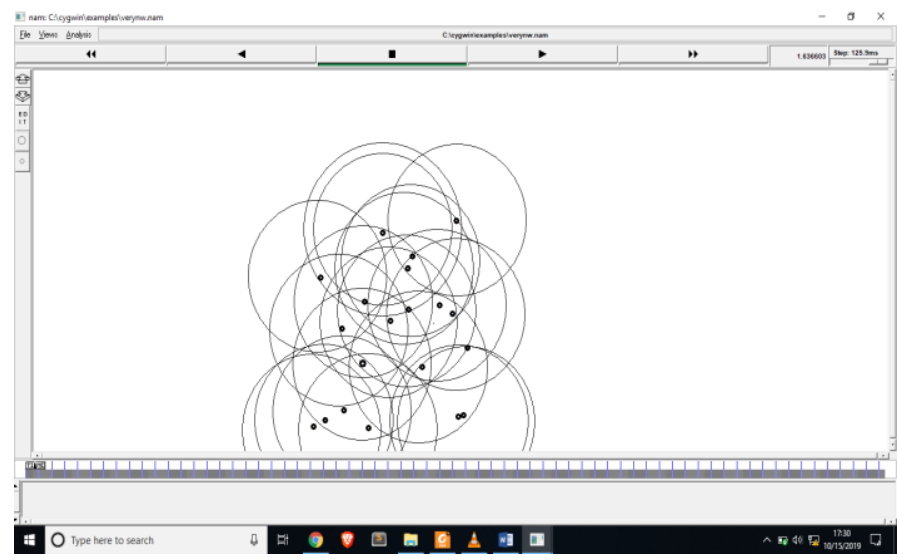

Fig 4:- Simulation of mobile node and their

\section{A. The Packet Delivery Ratio For Both New And Existing Dsr}

The following result were generated after executing the same tcl file in after and before modifying the DSR protocol in NS2.35 within the files dsragent.cc and dsragent.h. The researcher used the .tr file for evaluating the performance metrics such as packet delivery ratio and packet delay.

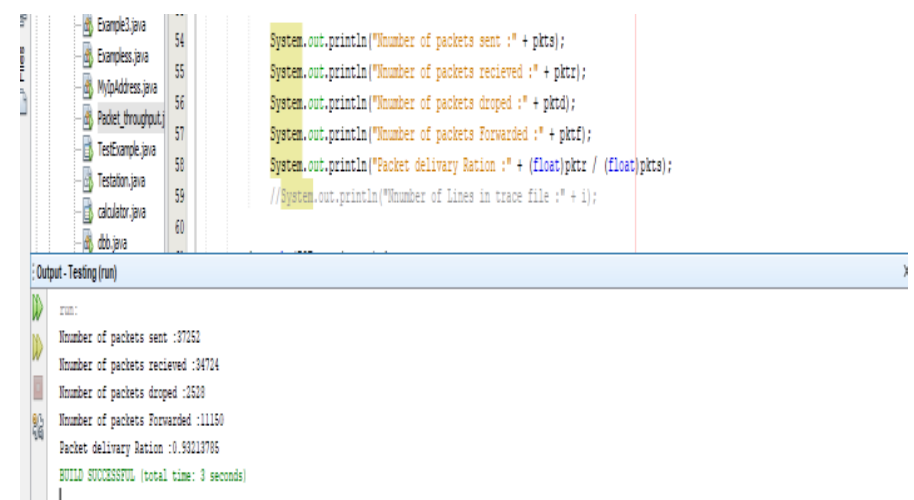

Fig 5:- Before DSR algorism modification

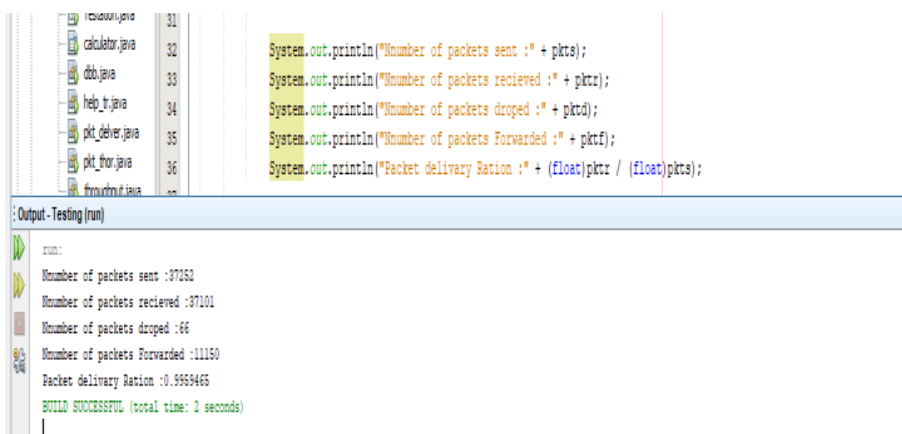

Fig 6:- Final modified DSR packet delivery ration

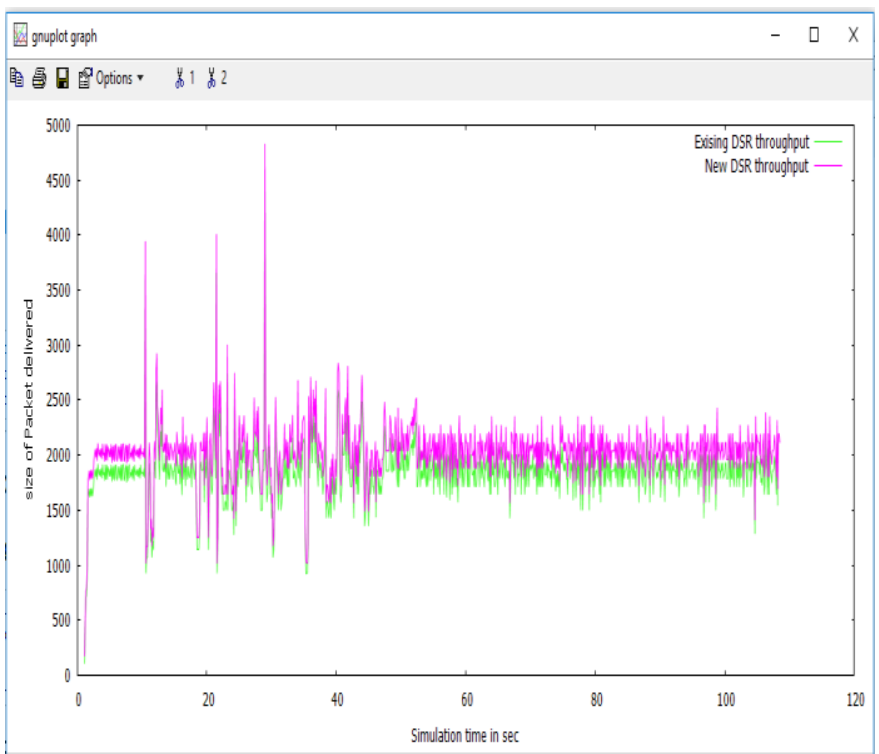

Fig 7:- Packet throughput in before and after the DSR algorism modification 


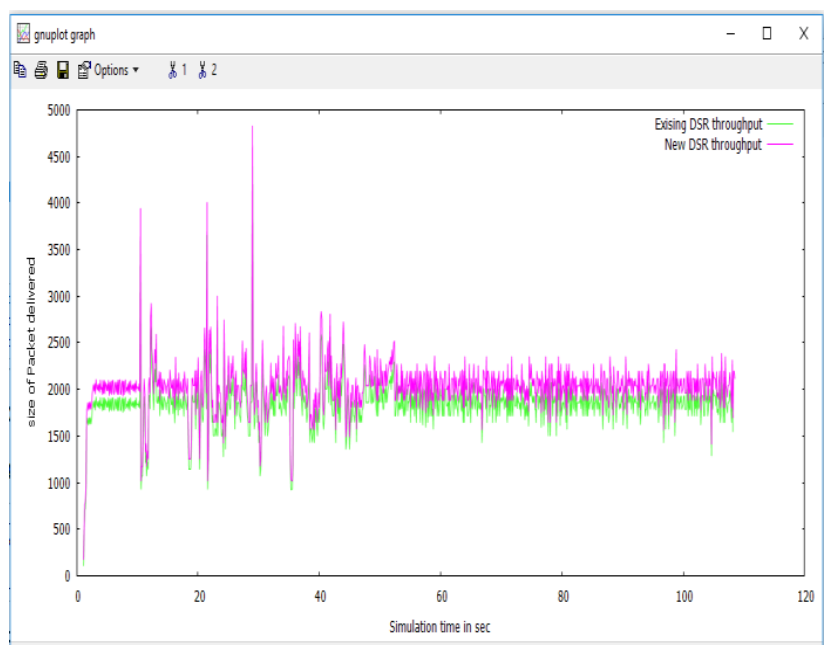

Fig 8:- The graph illustrates the difference between the existing and new DSR protocol related with packet delivery ration.

\section{B. End To End Delay Of New And Existing Dsr Protocol}

End-to-end Delay: the average time taken by a data packet to arrive in the destination. It also includes the delay caused by route discovery process and the queue in data packet transmission. Only the data packets that successfully delivered to destinations that counted.

$\sum$ ( arrive time - send time ) / $\sum$ Number of connections The lower value of end to end delay means the better performance of the protocol.

The researcher considered the second performance evaluation parameter which is end to end packet delay and the result were illustrated the graph below.

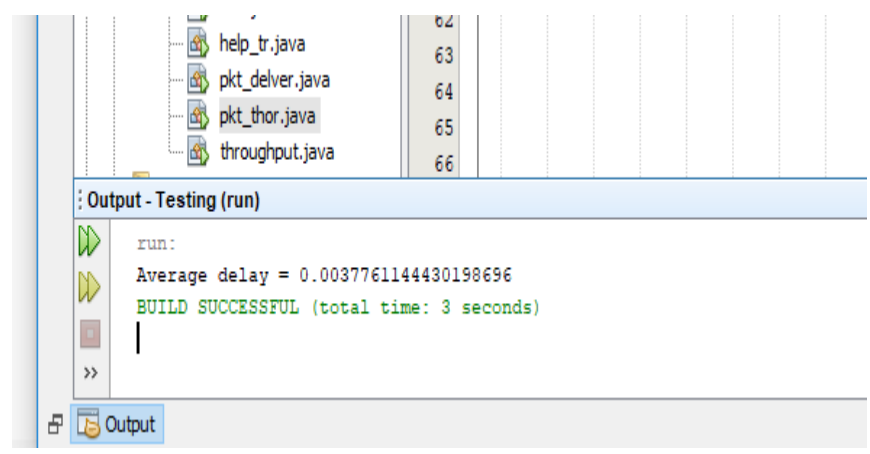

Fig 9:- New DSR end-to-end packet delay

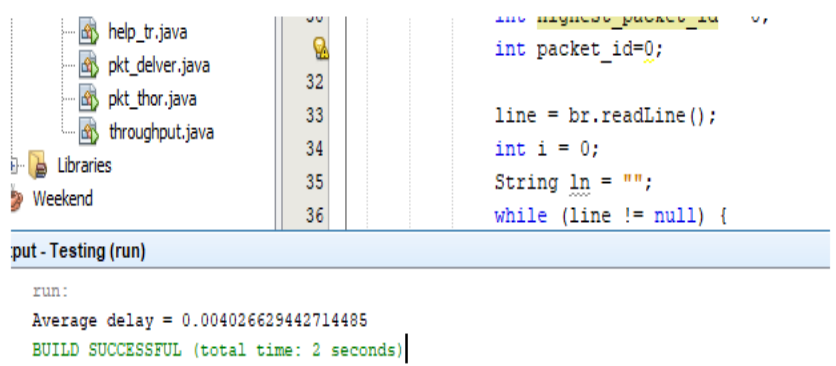

Fig 10:- Existing DSR end-to-end packet delay
ISSN No:-2456-2165

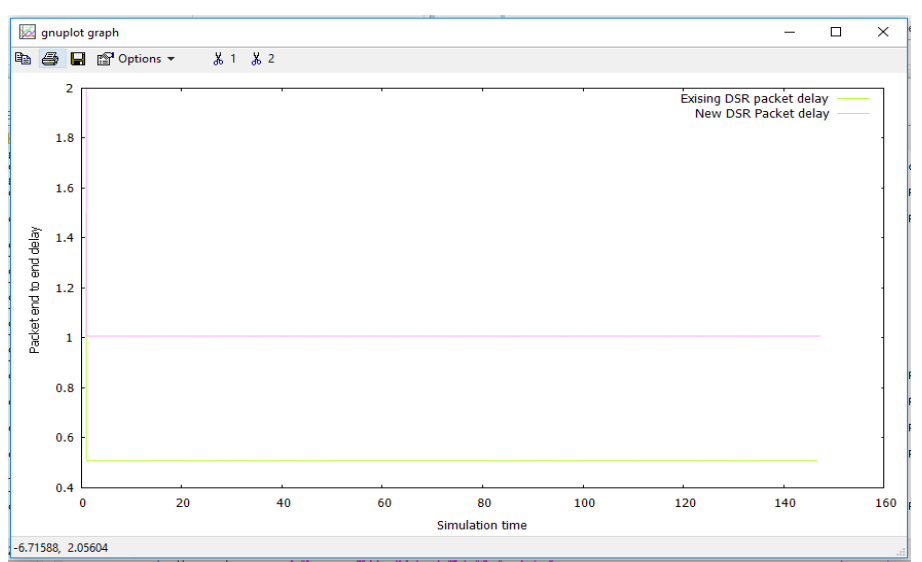

Fig 11:- The graph illustrates End to end packet delay in comparative view of DSR protocols in before and after algorism modification

\section{CONCLUSION}

In this research work, we planned to enhance the performance of DSR protocol by modifying the algorism by using the simulation tool (NS2.35) to test the metrics in order to check how far the difference recognized. We implemented and tested the algorism with simple MANET network simulation with 20 nodes within $150 \mathrm{sec}$; the parameters such as packet delivery ratio and end-to-end packet delay were evaluated and achieved promising output. Finally this research will be recommended to be used by future research work which may based from this outputs.

\section{REFERENCES}

[1] S. Z. B. Sadiya Mirza1, "INTRODUCTION TO MANET," pp. 17-20, 2018.

[2] R. Chau, "MANET's routing with prediction," 2012.

[3] G. Nair and N. J. R. Muniraj, "Prediction based Link Stability Scheme for Mobile Adhoc Networks,," IJCSI International Journal of Computer Science Issues, Vols. , vol. 9, no. 6, pp. pp. 401-408,, 2012.

[4] J. J. J. a. Shivashankar, " Energy Efficient Routing Protocol Based On DSR," S," ri Venkateshwara College of Engineering, VTU, Bangalore, India,, Vols. vol.7, no.5, , 2016 .

[5] S. I. M. J. H. S. H. Mohammed Humayun Kabir, "Detail Comparison of Network Simulators," pp. 1-16, 2014.

[6] L. Q. a. T. Kunz, "Increasing Packet Delivery Ratio in DSR by link prediction," IEE proceeding of 36th hawaii International conference on system science, pp. 5-6, 2002.

[7] M. Y. a. X. Z. Haojun Yang, "Link Available Time Prediction Based GPSR for Vehicular Ad Hoc Networks," 2017.

[8] Y. e. al, "Improving Routun performance in AODV witk link prediction in mobile adhoc network," 2015.

[9] K. G. P. a. A. Unnikrishnan, "Fuzzy Decision-Based Reliable Link Prediction Routing in MANET Using Belief Propagation," 2018. 
[10] M. T. a. M. T. C.Priyadharshini, "Predicting Route Lifetime for Maximizing Network Lifetime in MANET," ACS-International Journal in Computational Intelligence, Vols. Vol-3,Issue-1, Mar 2012. .

[11] P. S. a. D. K. Lobiyal, "DSR with link prediction using Pareto distribution," Prashant Singh and D. K. Lobiyal, "DSR with link pre IEEE International Conference on Networking and Information Technology, vol. pp. 29-33, 2010. .

[12] M. R. Geetanjali Sharma1, "Advancement in Dynamic Source Routing Protocol for MANETs," , International Journal of Computer Science and Mobile Computing,, vol. Vol.3 Issue.5, pp. pg. 428-433, 2014.

[13] Buchegger and J. L. Boudec, "“Performance analysis of the confidant protocol: (cooperative of nodes - fairness in dynamic ad hoc networks)," in Proc.,," IEEE/ACM Workshop on (MobiHoc'02), vol. pp. 226-336. , 2002, .

[14] S. J. G. Golsum Najafia, "A Stable Routing Protocol based on DSR Protocol for Mobile Ad Hoc Networks," Wireless and Microwave Technologies, vol. 3, pp. 1422, 2018.

[15] P. a. A.Unnikrishma, "Enhancing the performance of Routing protocol in MANET by predicting the link availablity through belief propagation," 2017.

[16] K. Z. a. A. S. Ismail, ", "Route Maintenance Approach for Link Breakage Predicttion in Mobile Ad-hoc Networks," ," International Journal of Advanced Computer Science and Applications, , Vols. vol. 2, no. 10, , pp. pp. 23-30,, 2011. 